\title{
Determination of antimicrobial activity of traditional spices extracts against clinical isolates in Dhaka city
}

\author{
Md. Hasibur Rahman, Muhammad Asaduzzaman and Md. Shahidul Kabir* \\ Department of Microbiology, Stamford University Bangladesh, 51, Siddeswari Road, Dhaka-1217, Bangladesh
}

Received 29 September 2021/Accepted 30 October 2021

\begin{abstract}
Spices are dried aromatic substances derived from plants and have demonstrated antimicrobial activity against pathogenic microorganisms. In the present study, a total of six spices turmeric (Curcuma longa), garlic (Allium sativum), black pepper (Piper nigrum), ginger (Zingiber officinale), clove (Syzygium aromaticum) and cinnamon (Cinnamomum verum) were evaluated for their antibacterial activity. Antibacterial activities of ethanol, propanol and water extracts were determined by agar well diffusion assay against previously isolated Klebsiella pneumoniae, Staphylococcus aureus from urine samples and Citrobacter spp. from throat swab samples. All spices examined in this study showed antibacterial activity in different types of extraction methods. Water, ethanol and propanol extracts exhibited anti-bacterial activity measured as zone of inhibition between $6 \mathrm{~mm}$ and $25 \mathrm{~mm}$ in diameter. Water extract of garlic (Allium sativum) showed the highest antibacterial activity (25mm) against clinical isolates of Staphylococcus aureus and Citrobacter spp. Water extract of other species showed the lowest antibacterial activity $(6 \mathrm{~mm})$ against throat swab isolates Staphylococcus aureus and Citrobacter spp. Spices which showed signifiant antimicrobial activities can be further studied for the isolation of active ingredients and development of novel drugs.
\end{abstract}

Keywords: Pathogenic microorganism, Agar well diffusion, Antibacterial activity, Spices.

\section{INTRODUCTION}

Spices have been considered as important ingredients of human diet that are collected from indigenous or exotic plans. In addition to enhancing flavor, aroma or strong taste, herbs and spices are also known for their preservative and medicinal value (1). Spices can be different parts of a plant such as flowers (Syzygium aromaticum), stems (coriander, Cinnamomum verum), as leaves (bay, mint, rosemary, laurel and oregano), fruits (red chilli, cumin, black pepper), rhizomes (Zingiber officinale), bulbs (garlic, onion), and other plant parts (1). Spices and herbs are rich sources of antioxidants. Due to antioxidant and anti-inflammatory properties, species have also been used to treat several diseases such as diabetes, atherosclerosis, neurodegenerative, or cancer (2-4). Studies showed that certain species demonstrated therapeutic effects against neurodegenerative cardiovascular diseases as well as inhibitory effect of spices on a variety of microorganisms (5-6). Garlic with its antibacterial properties and effective against acid-fast, gram-positive and gram-negative bacteria such as Salmonella, Escherichia coli, Pseudomonas, Proteus, Staphylococcus aureus, Escherichia coli, Salmonella, Klebsiella, Micrococcus, Bacillus subtilis, Clostridium, Mycobacterium, and Helicobacter (7). It has been documented that garlic exerts showed differential inhibition between harmful enterobacteria and beneficial intestinal microflora (7). On other hand, Eugenol, an active ingredient of clove is used for toothache as an antiseptic and possesses local anesthetic activity (8).

Food-borne illness caused by the most common bacteria such as Escherichia coli, Salmonella spp., Salmonella typhimurium, Listeria monocytogenes, Staphylococcus aureus, Clostridium botulinum, Vibrio spp. can cause serious symptoms such as, diarrhea, fever, vomiting, abdominal cramps and dehydration in susceptible hosts (9). Natural products and naturally derived components from different plants have applications in controlling these pathogenic bacteria in foods due to antimicrobial activity exhibited by different bioactive compound like alkaloids, flavonoids, isoflavonoids, tannins, cumarins, glycosides, terpens and phenolic compounds (10). This study is designed to determine the antibacterial properties of some common spices like turmeric (Curcuma longa), garlic (Allium sativum), black pepper (Piper nigrum), ginger (Zingiber officinale), clove (Syzygium aromaticum) and cinnamon (Cinnamomum verum) against some clinical isolates collected from the local diagnostic laboratories in Dhaka, Bangladesh.

\section{MATERIALS AND METHODS}

Collection and culture of clinical bacterial isolates. All bacterial isolates were collected from the Department of Microbiology of Stamford University Bangladesh, which was previously isolated from urine and throat swab samples of patients in a local diagnostic center, located in Dhaka city.

Study area and sample collection. Six categories of spices including turmeric (Curcuma longa), garlic (Allium sativum), black pepper (Piper nigrum), ginger (Zingiber officinale), clove (Syzygium aromaticum) and 
cinnamon (Cinnamomum verum) were collected from local grocery stores in Dhaka, Bangladesh, between March and June 2021. It was then transferred to the laboratory to conduct antimicrobial assay against bacterial isolated from clinical samples as described below.

Bacterial isolates. Five bacterial isolates, two from urine samples Klebsiella pneumonia, Staphylococcus aureus and the rest three from throa swabs Klebsiella pneumonia, Staphylococcus aureus and Citrobacter spp., were used in study. Pure cultures of these bacteria were obtained from a loca diagnostic center and further biochemically characterized in the Department of Microbiology of Stamford University Bangladesh following standard methods (11-15)

Preparation of crude extract. The spice samples were extracted following methods used in a previous research work with some modifications (16). For antibacterial activity $20 \mathrm{~g}$ of dry spice power was added to $100 \mathrm{ml}$ of propanol, methanol and water and put in a shaker for 24 hour at $120 \mathrm{rpm}$ at $37^{\circ} \mathrm{C}$. After 24 hours samples were centrifuged at $3000 \mathrm{rpm}$ for 10 minutes. Then supernatant was collected by filtering the centrifuged samples using Whatman filter paper and stored in a refrigerator at $4-8^{\circ} \mathrm{C}$. The stock solution was then diluted to various concentrations to determine the antibacterial activities. Three replicates were measured for each concentration.

Determination of Antibacterial activity using agar well diffusion method. The antimicrobial activity of the spice extracts was determined by agar well diffusion method. The bacteria were grown in Muller Hinton broth (Himedia Laboratories Ltd., India) to match the turbidity of $0.5 \mathrm{McFarland}$ standards to be inoculated on Muller-Hinton Agar (17). After drying the plates for 15 minutes after inoculation, wells were punched using sterile cork borers. Then the wells were filled with $50 \mu \mathrm{l}$ of spice extracts (ethanol, methanol and water). Commercially available Gentamycin $(10 \mu \mathrm{g})$ discs were used as a positive control. The plates were incubated for 24 hours at $37^{\circ} \mathrm{C}$ which allowed spice extracts to diffuse through the agar media to form zones of inhibition. The diameters of the zone of inhibition (in millimeter) were determined against propanol, methanol and water extract of ginger, garlic, turmeric, black pepper, clove and cinnamon against five clinical isolates. Extracts were considered positive for antibacterial property when the zone of inhibition was $\geq 6 \mathrm{~mm}$ in diameter.

\section{RESULTS AND DISCUSSION}

Spices and herbs have been commonly recognized by many cultures to enhance the flavor and aroma of food. Early culture also reorganized the values of using spices for new sources of diseases medication procedure (17-19). Many of the species used in traditional medicine are readily available in rural areas at a lower cost than conventional modern medicine (19). Spices in the earlier decades showed that the growth of different bacteria, yeasts and molds can be inhibited by onion, garlic, clove, cinnamon, thyme, sage and other spices. Although, a primary purpose of species is to increase the flavor and aroma of food, the medicinal, antimicrobial and antioxidant properties of spices have also been documented (20). This study was performed to evaluate the antibacterial activity of water, ethanol and methanol extracts of some common spices against pathogenic bacteria found in different clinical samples. Antibacterial activity of different spices in different solvents against pathogenic microorganism isolated from urine and throat swab samples are shown on Table 1 and 2

Considering pathogenic microorganism present in urine and throat swab samples, ginger, garlic, turmeric, black pepper and clove were found to exhibit the bactericidal effects against Klebsiella pneumonia, Staphylococcus aureus and Citrobacter sp. The highest zone of inhibition was recorded (25 $\mathrm{mm}$ ) for water extract of garlic against Citrobacter spp. (throat swab) and Staphylococcus aureus (throat

Table1. Antibacterial activity (zone diameters in $\mathrm{mm}$ ) of different Spices extracted in different solvents against pathogenic microorganisms present in urine samples.

\begin{tabular}{|c|c|c|c|c|c|c|c|}
\hline Microorganisms & $\begin{array}{l}\text { Extraction } \\
\text { methods }\end{array}$ & Ginger & Garlic & Turmeric & $\begin{array}{c}\text { Black } \\
\text { pepper }\end{array}$ & Clove & Cinnamon \\
\hline \multirow{5}{*}{$\begin{array}{l}\text { Klebsiella } \\
\text { pneumoniae } \\
\text { (urine) }\end{array}$} & DW (Boil) & 12 & 11 & 11 & 12 & 12 & 10 \\
\hline & $\mathrm{DW}(\mathrm{RT})$ & 10 & 11 & 13 & 9 & 11 & 8 \\
\hline & Methanol & 10 & 12 & 9 & 14 & 12 & 9 \\
\hline & Propanol & 14 & 11 & 13 & 13 & 10 & 11 \\
\hline & DW (Boil) & 8 & 9 & 11 & 9 & 12 & 11 \\
\hline \multirow{3}{*}{$\begin{array}{l}\text { Staphylococcus } \\
\text { aureus (urine) }\end{array}$} & DW (RT) & 8 & 16 & 11 & 9 & 12 & 8 \\
\hline & Methanol & 14 & 12 & 13 & 13 & 12 & 12 \\
\hline & Propanol & 12 & 9 & 12 & 12 & 12 & 9 \\
\hline
\end{tabular}

Table 2. Antibacterial activity (zone diameters in $\mathrm{mm}$ ) of different Spices extracted in different solvents against pathogenic microorganism present in throat swab samples.

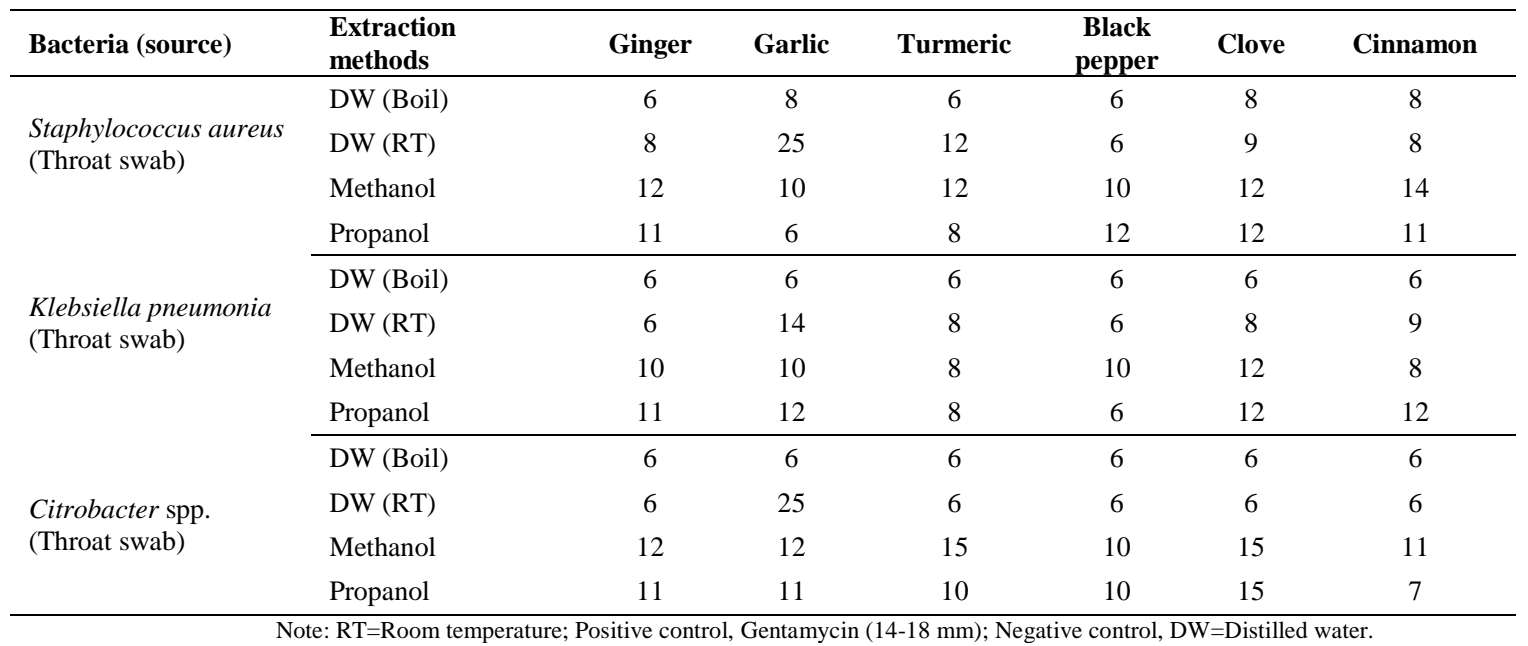


swab). The findings are in agreement with previous studies (21-23) whereas garlic was found to be significant antimicrobial agent. Propanol extract of clove and methanol extract of turmeric also showed effective antimicrobial activity $(15 \mathrm{~mm})$. The result obtained for the clove extract is supported by a previous report (24). The lowest antimicrobial activity $(6 \mathrm{~mm})$ observed in water extract of species considering isolates from throat swab samples. Overall, methanol and propanol extract species showed maximum antibacterial activity when compared to water extract species. The organic solvent extraction of herbs and spices was better because methanol and propanol is an organic solvent and dissolves more organic compounds, resulting in the liberation of the greater amounts of active antimicrobial components (25).

In each experiment, we considered Gentamicin (10 $\mu \mathrm{g})$ and distilled water as positive and negative control, respectively. In all the cases, Gentamicin (10 $\mu \mathrm{g}$ ) produced $14-18 \mathrm{~mm}$ zone of inhibition against all isolates from both urine and throat swab samples, however, negative controls didn't show any zone of inhibition (26).

Based on these results, all species included in this study showed notable antimicrobial properties. Variations of the results may be due to the use of different methods, variations in concentrations, test environments etc. Antimicrobial activity of different kind of spices may depend on several specific factors, including varieties of spices, particular microbial species and its occurrence level, concentration and composition of spices, processing conditions, substrate composition etc.

\section{CONCLUSION}

After analyzing the results obtained from this study, it can be inferred that different extracts of spice have significant amount of antibacterial activity. However, depending on which solvent is being used for extraction, the antibacterial activities were found to vary. The organic solvents are comparatively better than water for extraction of spice. Herbs, spices and derivatives could be alternatives for inclusion in food conservation systems and antimicrobial agents. For future studies, the bioactive compounds of spice should be isolated by using phytochemical analysis and evaluated in detail for their potential to develop more efficient therapeutic drugs and novel antibiotics.

\section{ACKNOWLEDGEMENT}

We thank the Department of Microbiology, Stamford University Bangladesh, for providing technical and the laboratory support throughout our study.

\section{REFERENCES}

1. De Souza EL, Stamford TLM, Lima EO, Trajano VN and Filho JMB.
2005. Antimicrobial effectiveness of spices: an approach for use in food conservation systems. Braz. arch. biol. technol. 48:549-558

2. Patra K, Jana K, Mandal DP and Bhattacharjee S. 2016. Evaluation of the antioxidant activity of extracts and active principles of commonly consumed Indian spices. J. Environ. Pathol. Toxicol. Oncol. 35:299315

3. Singhal P, Singla N, Sakhare D and Sharma KA. 2017. A comparative evaluation of in vitro antioxidant activity of some commonly used spices of northern India. Nat. Prod. J. 7:131-136.

4. Ene-Obong H, Onuoha N, Aburime L and Mbah O. 2017. Chemical composition and antioxidant activities of some indigenous spices consumed in Nigeria. Food Chem. 238:58-64.

5. Gorinstein S, Leontowicz H, Leontowicz M, Namiesnik J, Najman K, Drzewiecki $\mathrm{J}$ et al. 2008. Comparison of the main bioactive compounds and antioxidant activities in garlic and white and red onions after treatment protocols. J. Agric. Food Chem. 56:4418-4426.

6. Gorinstein S, Leontowicz H, Leontowicz M, Jastrzebski Z, Najman $\mathrm{K}$, Tashma $\mathrm{Z}$ et al. 2010. The influence of raw and processed garlic and onions on plasma classical and non-classical atherosclerosis indices: Investigations in vitro and in vivo. Phytother. Res. 24:706714.

7. Bayan L, Koulivand PH and Gorji A. 2014. Garlic: a review of potential therapeutic effects. Avicenna J. Phytomedicine 4(1):1-14.

8. Suresh P, Ingle VK and Vijayalakshmi V. 2018. Antibacterial activity of eugenol in comparison with other antibiotics. J. Food Sci. Technol. 5(12):256-257.

9. Chandarana HS, Baluja S and Chanda S. 2005. Comparison of antibacterial activities of selected species of Zingeberaceae family and some synthetic compounds. Turk. J. Biol. 29:83-97.

10. Hoque MM, Bari ML, Juneja VK and Kawamoto S. 2008. Antimicrobial activity of clove and cinnamon extract against food borne pathogens and bacteria with their essential oils. Rep. Nat. Food Res. Inst. 72:9-21.

11. Das JS, Feroz F, Tahera J, Das KK and Noor R. 2014. Assessment of microbiological contamination and the in vitro demonstration of the anti-bacterial traits of the commonly available local fruit blend within Dhaka Metropolis. J. Pharmacogn. Phytochem. 3(1):73-77.

12. Cappuccino JG and Sherman N. 1996. Microbiology - A laboratory manual. The Benjamin/Cummings Publishing Co., Inc., Menlo Park, California.

13. American Public Health Association (APHA). 1998. Standard methods for the examination of water and wastewater. American Public Health Association, Washington, D.C.

14. Sultana T, Rana J, Chakraborty SR, Das KK, Rahman T and Noor R. 2014. Microbiological analysis of common preservatives used in food items and demonstration of their in vitro anti-bacterial activity. Asian Pac. J. Tropi. Dis. 4(6):452-456.

15. Akon T, Das KK, Naher LN and Noor R. 2015. Demonstration of in vitro anti-bacterial activity of the popular cosmetics items used by the Dhaka locality. Asian Paci. J. Trop. Dis. 5(1):S121-S126.

16. Uddin MA, Hasan KW and Jamal JB. 2017. Detection of microbial proliferation \& assessment of antibacterial activity of spices collected from various locations of Dhaka city, Bangladesh. Stam. J. Microbiol. 7(1):10-13

17. Liu Q, Meng X, Ya L, Zhao CN, Tang GY and Li HB. 2017. Antibacterial and Antifungal Activities of Spices. Int. J. Mol. Sci. 18:1283.

18. Sah SN, Khanal H and Acharya DR. 2020. Antibacterial Activity of Common Spices Extracts on Bacterial Isolates Found in Kachhila, a Newari Cuisine. TUJM. 7(1):8-18

19. Raj N and Arulmozhi K. 2013. Efficacy of heat treatment on the in vitro antioxidant activity of selected spices. Int. J. Cur. Microbiol. Appl. Sci. 2:13-18.

20. Clinical and Laboratory Standard Institute (CLSI). 2011. Performance standards for antimicrobial susceptibility testing; twenty-first informational supplement. CLSI document. M100-S21.

21. Rahman MS, Al-Sheibani HI, Al-Riziqi MH, Mothershaw A, Guizani $\mathrm{N}$ and Bengtsson G. 2006. Assessment of the anti-microbial activity of dried garlic powders produced by different methods of drying. Int. J. Food Prop. 9:503-513.

22. Islam K, Rowsni AA, Khan MM and Kabir MS. 2014. Antimicrobial activity of ginger (Zingiber officinale) extracts against food-borne pathogenic bacteria. Int. J. Sci. Environ. Technol. 3(3):867-871.

23. Arora DS and Kaur J. 1999. Antimicrobial activity of spices. Int. J. Antimicrob. Agents. 12:25-262.

24. Cowan MM. 1999. Plant products as antimicrobial agents. Clin. Microbiol. Rev. 12:564-582.

25. Al Farraj DA, Gawwad MRA, Mehmood A, Alsalme A, Darwish NM, Zaqri NA et al. 2020. In-vitro antimicrobial activities of organic solvent extracts obtained from Dipacadi viride (L.) Moench. J. King Saud Univ. Sci. 3(32):1965-1968.

26. ICMSF. 1998. Microorganisms in foods. Sampling for microbiological analysis: Principles and specific applications, Second edition. University of Toronto Press, Toronto. 